\title{
Cause Analysis of the Secondary Mountain Disaster Chain in Wenchuan Earthquake
}

\author{
Ranran Pei, Zhenqiang Ni, Zhaobo Meng*, Baoliang Zhang*, Yuanyuan Geng
}

School of Architecture \& Civil Engineering, Liaocheng University, Liaocheng, China

\section{Email address:}

nizhenqiang@1cu.eud.cn (Zhenqiang Ni), mengzhaobo@1cu.eud.cn (Zhaobo Meng), zhangbaoliang@1cu.edu.cn (Baoliang Zhang), gengyuanyuan@163.com (Yuanyuan Geng)

${ }^{*}$ Corresponding author

\section{To cite this article:}

Ranran Pei, Zhenqiang Ni, Zhaobo Meng, Baoliang Zhang, Yuanyuan Geng. Cause Analysis of the Secondary Mountain Disaster Chain in Wenchuan Earthquake. American Journal of Civil Engineering. Vol. 5, No. 6, 2017, pp. 414-417. doi: 10.11648/j.ajce.20170506.24

Received: November 14, 2017; Accepted: November 28, 2017; Published: December 28, 2017

\begin{abstract}
Earthquakes and their secondary disaster chains are often destructive. It poses a great threat to the social development, economic development and cultural development by studying the typical disaster chains in the 5.12 major earthquakes in 2008. This paper analysis of its universal causes and summarizes characteristics of the disaster to prevent and control the harm caused by earthquakes and their secondary disaster chain more effectively is the urgent need of I in the contemporary society. In order to study the causes of the mountain secondary disaster chain, with the typical secondary mountain disaster chain of the 2008 earthquake in Wenchuan as an example, this paper analyzes the causes of disasters using field investigation, remote sensing technology, the method of data analysis. The study found that the typical disaster chains of Landslide - Debris flow - Dammed Lake, Earthquake - Landslide - Dammed Lake - Debris flow are affected by topography and geomorphology. At the same time, it is also related to precipitation, accumulation bodies and other factors. Ginkgo Mozigou located in Chaping mountains The relative height difference is very large, very steep. A series of secondary disasters are caused by heavy rainfall and a large amount of debris accumulation the dam on the river at Shikan home, close to the two fault zones. The slump accumulation bodies slow down in the whole shape.
\end{abstract}

Keywords: Wenchuan Earthquake, Secondary Mountain Disaster Chain, Cause Analysis, Slump Accumulation

\section{Introduction}

The mountain disaster chains often cause destructive hazards, and occur at home and abroad. Columbia Ruiz Volcano Disaster Chain killed 25 thousand people in Indonesia, which may Luocheng ruins in 1985 [1]. A landslide debris flow disaster chain out broke in a village in Central Java province, which killed more than 200 people in January 2006 [2]. The debris flow hazard chain had also occurred in 5.12 Wenchuan earthquake.

Attention of secondary disasters caused by the Wenchuan earthquake has wide attended by experts. Chen Yuntai, Xu Hong [3], analyzed on the cause, disaster and treatment of the secondary disasters in Wenchuan earthquake. Deng Ling and Li Xiaoyan put forward countermeasures for the reconstruction of ecological environment in Wenchuan earthquake stricken area [4].
Wang Jicheng and Zhou Yun [5-7] put forward countermeasures for the secondary disasters after the Wenchuan earthquake. So far, many experts have carried on the analysis forecast and the experimental simulation to the earthquake secondary disaster [8-13], and some scholars have done the related research on the secondary disaster after earthquake to the reconstruction of the disaster, but the research on the case analysis of the secondary mountain disaster chain from the angle of disaster is less.

This paper adopted field survey, remote sensing technology, data analysis and other methods to analyze the ginkgo Mozigou collapse (landslide) - Lake and the origin of debris flow disaster chain Wenjiaba - Lake Earthquake landslide debris flow disaster chain. 


\section{Ginkgo Mozigou Collapse (landslide) - Lake Debris Flow Disaster Chain}

The Wenchuan earthquake caused both source and channel Mozigou basin mountain massive collapse, blocking off the channel, forming more than 10 damming body. After entering the flood season, under the action of the torrential rain occurred 75 times successively in the form of debris flow surges [14-16]. The three debris flows on August 15th, August 6th and 2008 were larger. Blocking the main stream of Minjiang River, the longest blocking of Minjiang River reaches $15 \mathrm{~min}$. The emergence of the debris flow will Mozigou Mizoguchi about $500 \mathrm{~m}$. Duwen highway completely buried, including a road bridge. To December 2008, field investigation, Mozi gully debris flow accumulation fan with an average thickness of about $30 \mathrm{~m}$, the accumulation body side is about 1 million and 500 thousand $\mathrm{m}^{3}$ [17-18]. When the debris flow completely blocked the Minjiang River, the water level of the dammed lake formed in the upper reaches was about $20 \mathrm{~m}$. The debris flow blocking riverbed up river burst, keep a lake water depth of about $8 \mathrm{~m}$ in the upstream, some houses in the upper reaches of the Minjiang River on the right bank of Ginkgo Township village is a bowl of water was submerged in water.

Mozigou collapse (landslide) - Lake disaster chain is composed of debris flow earthquake formation of debris flow in strong rainstorm stimulated group, disaster mode and debris blocking river formed the lake. According to the types of Yingxiu to Beichuan should belong to the space chain in earthquake collapse (landslide) - lake of disaster chain of debris flow. With the overall chain effect of disaster chain is strong, easy to disaster, serious, complex mechanism, and the overall characteristics of difficult to control. As a result of the disaster chain is caused by rainstorm excitation, and rainfall factors in Ginkgo Mozigou disaster chain are particularly prominent.

\subsection{The Influence of Geology and Geomorphology}

Mozigou is located in the Longmen mountains extension of Chaping Mountains, which belong to the Beichuan Baoxing anticlinorium fold belt in the geological structure, tectonic mountain Penguan complex. Mozigou basin area of $7.20 \mathrm{~km}^{2}$, the main channel length of $3.81 \mathrm{~km}$, the highest elevation in the river basin left the source channel, that was at an altitude of $3556 \mathrm{~m}$ and the minimum altitude of $987 \mathrm{~m}$, the relative height of $2569 \mathrm{~m}$, the main channel of the average longitudinal slope is 674.3 per thousand. Gully slope is very steep. Mozigou River meander Valley, valley bottom was "V" shaped Valley, local valleys in the upper valley. The valley slope angle is conducive to the accumulation and transport of loose solid material in 25 degrees above. The terraces on both sides of the valley are scattered, and the NO.I - V terrace with different scales can be seen among them. The NO.I terrace is well preserved, and more than the second grade terrace is only partially survived, which indicates this kind of geological landform is easy to cause disaster.

\subsection{The Influence of Rainfall Conditions}

According to the statistics of the rainfall stations of the grass slope township and the lower cable bridge near the mill gully, the average annual rainfall of grass township is 734.5 $\mathrm{mm}$, and the average annual rainfall of the cable-stayed bridge is $653.8 \mathrm{~mm}$. The annual rainfall mainly concentrated in the flood season (from May to September), which was the single peak. In the climate of the region belong to the mountainous subtropical humid monsoon climate. It is rainy and waterlogged, and the autumn rain is serious. Four seasons, summer heat, winter is mild, temperature, frost free period is the longest, insufficient light (the state, less Sunshine Center) climate characteristics.

\subsection{The Influence of Seismic Beng Accumulation Body}

A large number of beng accumulations have been accumulated in the channel after the earthquake gully. In December 2008, the situation was studied, and the average thickness of Mozigou accumulation of debris flow fan is about 30 meters. The accumulation body side is about 1 million and 500 thousand $\mathrm{m}^{3}$ (Figure 1). A large number of deposits decline in water, resulting in river blockage, the formation of lake.

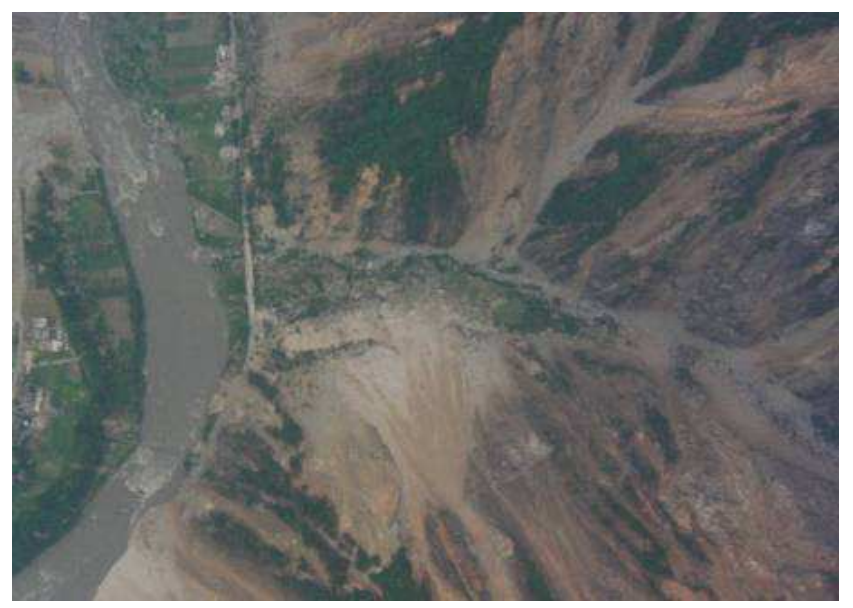

Figure 1. Mizoguchi earthquake aerial remote sensing images (2008. 05. 26).

\section{The Earthquake Lake Wenjiaba Landslide Debris Flow Disaster Chain}

Wenjiaba is located in the south of Pingwu County town, which is located on the River tributary of the Fujiang River stone. Because of the whole landslide right mountain about $6000000 \mathrm{~m}^{3}$ occurs under the action of earthquake formation capacity was $686 \mathrm{~m}^{3}$, more than $25 \mathrm{~m}$ of landslide dam. Because the dam is mainly limestone and metamorphic rock strong weathering slope soil and residual soil with crushed stone, and its material is loose and the dam stability is poor. The rescue workers immediately excavated a flood diversion channel on the damming body, temporarily reducing the water level of the dammed lake. But because of Wenjiaba upstream of Maanshi Lake flood, a large amount of water, the 
Wenjiaba Lake diversion channel through the great gap. A large amount of debris and silt will fill up $2 \sim 3 \mathrm{~km}$ of the lower reaches of the river, and the thickness of the deposited soil reaches $23 \mathrm{~m}$. A small part of the housing and the phosphate rock buried, causing serious debris silting disasters.

\subsection{The Influence of Geology and Geomorphology}

Wenjiaba Lake area is complex geological structure along the Ping Tong Town - Nanbazhen North East trending with the central north section of Longmen Mountain Fault Zone, and Pingwu - Qingchuan fault zone. The fault block area between the central fault Zone of Longmen Mountain and the fault zone of the front mountain is composed of Silurian and Devonian. NO.II - Ping Tong Town - Nanbazhen North East fracture belt and Pingwu - Qingchuan fault zone by the clamping block. The southwest segment is mainly composed of Silurian, and the northern part consists of metamorphic strata of Nanhua to Sinian system, which is the main shock zone of Wenchuan earthquake.

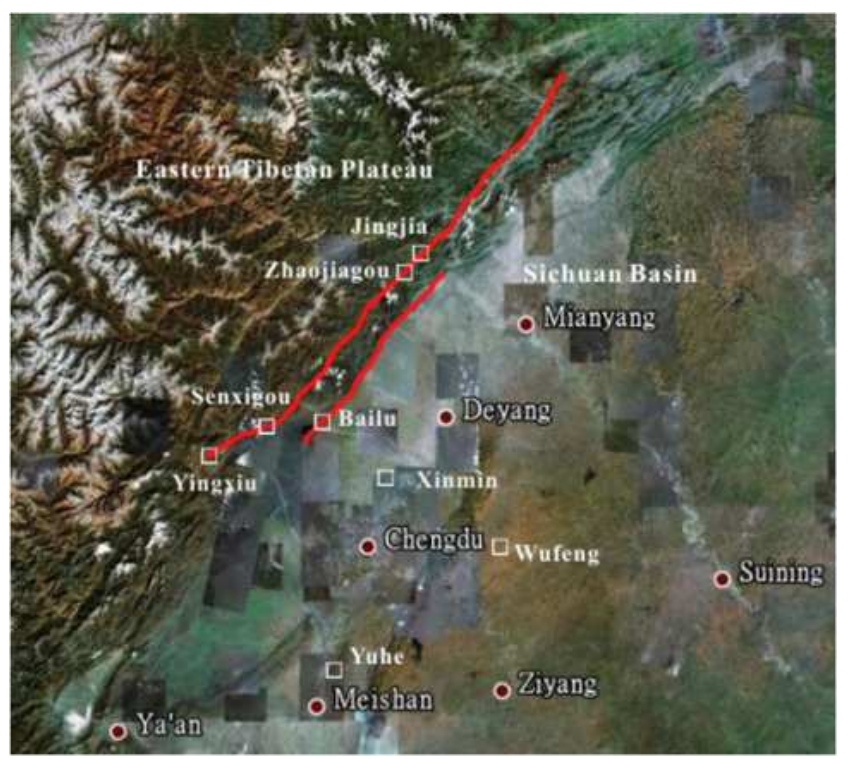

Figure 2. Regional river basin distributions (Jianjin Cao, et al, 2017).

A typical landscape is located in the mountains around the basin. Longmen mountain area is mainly composed of a mountain near the North West to the east. The Jiaoziding peak is elevation of $3045 \mathrm{~m}$, and the lowest point is in the South Fujiang River confluence of $700 \mathrm{~m}$ dam. The vertical is height of $2256 \mathrm{~m}$, and the maximum distance is $16.94 \mathrm{~km}$. Located in the tributary of the left bank of river, the shape of the basin is a typical pattern of the plume. The basin area is $158 \mathrm{~km}^{2}$, and the confluence of the catchment area is large (Figure 2).

\subsection{The Influence of Slump Accumulation}

The lithology formation of the Yu Wen Jia landslide is the black manganese - carbonaceous silicon phyletic in the Qiujiahe formation. White clouds limestone is in the central. The lower part contains manganese siliceous rocks, youfang group metamorphic crumbs sandstone, Shiying sandstone, siltstone.

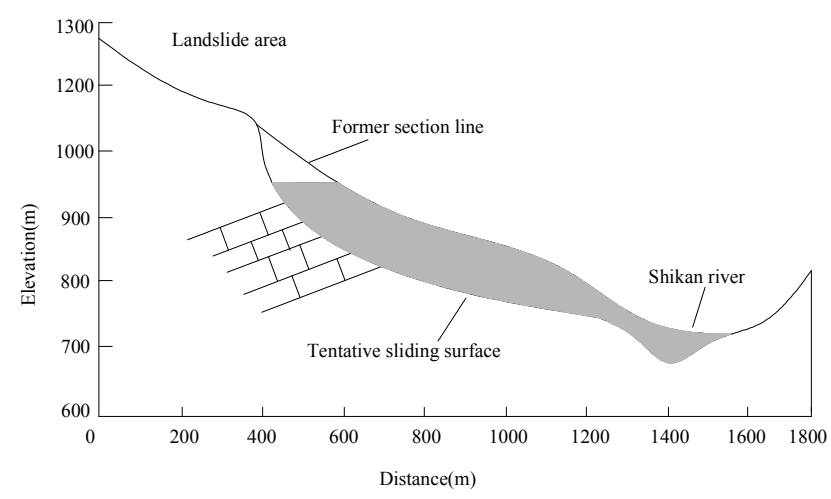

Figure 3. Schematic diagram of Wenjiaba landslide profile.

From the Figure 3, the accumulation body morphology integrity of Wenjiaba landslide, a square shaped stacking approximation, spreading in the river on the slope and rock ridge (Figure 3). The accumulation body slope than the original slope slightly slow, about 25 degrees. The landslide material is mainly composed of yellow, yellow brown soil and Quaternary layers of Cambrian altered sandstone and sandstone of gravelly soil. The transverse tensile fractures on the surface of the accumulation bodies develop, and the surface is stepped or steep in shape. The uplift phenomenon is not very obvious, basically cannot see the rollover phenomenon and slope of rock and soil, scattered vegetation is still in order. These characteristics show Wenjiaba landslide, the relatively slow movement characteristics of decline, and the movement of landslide to traction activities.

\section{Conclusion}

Ginkgo Mozigou collapse (landslide) - Lake debris flow disaster chain is easy to accumulate and carry loose solid matter and increase its harm. It has the characteristics of rainy, waterlogged, clear seasons and insufficient light. Under the influence of such climate characteristics, especially the precipitation is large and concentrated. It leads to the occurrence of secondary disaster chain leading to the occurrence of secondary disaster chain at the same time. It is also related to a large number of landslides and landslides accumulated after the earthquake. A large number of accumulation bodies fall into the water, resulting in river blockage and formation of dammed lakes. At the same time, it is related to the precipitation and the landslide accumulation factors. The earthquake - Lake Wenjiaba landslide debris flow disaster chain Wenjiaba Lake area located in the complex geological structure, affected by the geological features. The overall shape of intact Wenjiaba landslide develop surface transverse tensile fracture having a multi stepped or steep shape, uplift, soil tumbling phenomenon is not obvious. The general causes of the disaster chain can be obtained from the two cases in this paper, which are related to the geology and 
geomorphology and the factors of avalanche accumulation. Different regions have different landlord characteristics and different precipitation conditions. In the earthquake, a special form of slump accumulation is formed in this area

\section{Acknowledgements}

The research described in this paper was financially supported by the National Natural Science Foundation of China (NO. 51378245), the graduate student education innovation projects in shandong province (NO. SDYY16102) and the Doctoral Research Foundation of Liaocheng University (2017).

\section{References}

[1] P. Cui, "Progress and prospects in research on mountain hazards in China," Progress in Geography, vol. 33, 2014, pp. 146-151.

[2] D. L. Zhong, H. Xie, F. Q. Wei, H. J. Liu and J. F. Tang, "Discussion on Mountain Hazards Chain," Journal of mountain science, vol. 31, 2013, pp. 314-326.

[3] Y. Tao, K. H. Hu, Y. Z. Tian, Y. G. Ge and X. C. Chen, "Distribution and Characteristics of secondary mountain hazards triggered by ludian earthquake in Yunnan," Journal of earth sciences and environment, vol. 37, 2015, pp. 84-93.

[4] C. Miao, M. T. Ding, J. Wang, P. Zhou, "Distribution characteristics and cause of secondary mountain hazards in lushan earthquake-stricken area," Resources and environment in the Yangtze basin, vol. 23, 2014, pp. 1572-1579.

[5] F. Liu, X. Mao, Y. Zhang, et al, "Risk analysis of snow disaster in the pastoral areas of the Qinghai-Tibet Plateau," Geogr Sci, vol. 24, 2014, pp. 411-426.

[6] P. Cui, Q. Zou, L. Z. Xiang, et al, "Risk assessment of simultaneous debris flows in mountain townships," Prog Phys Geog, vol. 37, 2013, pp. 516-542.

[7] P. Cui, F. H. Su, Q. Zou, N. S. Chen and Y. L. Zhang, "Risk assessment and disaster reduction strategies for mountainous and meteorological hazards in Tibetan Plateau," Science China Press, vol. 60, 2015, pp. 3067-3077.
[8] S. H. Cao, Y. S. Wang and J. X. He, "Characteristics and disaster model of co-seismic landslides triggered by the Kangding Ms 6.3 earthquake on the $22^{\text {th }}$ of Nov. Sichuan province, China," The Chinese Journal of Geological Hazard and Control, vol. 26, 2015, pp. 87-93.

[9] X. Z. Li and J. M. Kong, "Comparative analysis of development law and characteristics of secondary geo-hazard induced by Lushan and Wen-chuan earthquakes," Joural of Natural Disasters, vol. 23, 2014, pp. 11-18.

[10] X. Q. Chen, P. Cui, Y. You, et al, "Secondary mountain disasters induced by the 4.20 Lushan earthquake and disaster mitigation," Earth Science Frontiers, vol. 20, 2013, pp. 29-34.

[11] C. Liu and Z. Liu, "Consultation for the scientific spirit in geological hazard and control," Hydrogeology and Engineering Geology, vol. 40, 2013, pp. 1-6.

[12] Y. H. Luo and Y. S. Wang, "Mountain slope ground motion topography amplification effect induced by Wenchuan earthquake," Journal of Mountain Science, vol. 2, 2013, pp. 200-210.

[13] Y. Luo, V. D. Gaudio, R. Huang, et al, "Evidence of hillslope directional amplification from accelerometer recordings at Qiaozhuang (Sichuan-China)," Engineering Geology, vol. 7, 2014, pp. 193 207.

[14] G. Y. Fu, S. H. Gao, G. Q. Zhang, et al, "Gravitational isostasy background and surface deformation response characteristics of the2015 Nepal Ms 8.1 earthquake," Chinese Journal of Geophysics, vol. 58, 2015, PP. 1900-1908.

[15] P. Li, S. Q. Qin, L. Xue, et al, "On the seismogenic process of the 25 April $2015 \mathrm{Mw} 7.8$ earthquake and future earthquake situation," Chinese Journal of Geophysics, vol. 58, 2015, pp. $1827-1834$.

[16] F. H. Su, P. Cui, J. Q. Zhang, et al, "Rock fall and landslides susceptibility assessment in Lushan earthquake region," Journal of Mountain Science, vol. 31, 2013, pp. 502 509.

[17] L. Y. Ye and Y. H. Li, "Features of the 2014 Lu-dian earthquake in Yunnan Province and its implication to the consequent rehabilitation and reconstruction," Journal of Yunnan Normal University, vol. 46, 2014, pp. 1-7.

[18] X. W. Xu, G. Y. Jiang, G. H. Yu, et al, "Discussion on seimogenic fault of the Ludian Mw 6 earthquake and its tectonic attribution," Chinese Journal of Geophysics, vol. 57, 2014, pp. 3060-3068. 